\title{
Customized PMSM Design and Optimization Methodology for Water Pumping Applications
}

\author{
Carlos Candelo-Zuluaga, Jordi-Roger Riba, Antonio Garcia Espinosa, Pere Tubert Blanch
}

\begin{abstract}
The need to reduce water pumps size to achieve compact designs adapted to multiple working points opens new fields of study. PMSMs are the preferred choice due to outstanding torque-speed range capabilities. This paper presents a methodology to design and optimize PMSMs by defining the desired torque-speed-efficiency map, adapting its performance to the hydraulic characteristics of the water pump. Once the hydraulic efficiency is known, an initial PMSM reference torquespeed-efficiency map is defined according to the objective motor performance, including the distribution of power losses and the power rating of the selected application. The designer has full freedom to define the efficiency levels and distribution along the torque-speed map. The design optimization algorithm achieves the PMSM characteristics which adjust as much as possible to the defined performance. This methodology uses ultra-fast finite element analysis by applying magneto-static computations and a time-space conversion to compute the iron losses, reducing the computational requirements. The torque-speed-efficiency map is calculated by applying a direct-quadrature electrical model. The objective function uses a novel image comparison technique that allows comparing the similarity between the objective and optimized maps. The methodology is validated experimentally by designing and testing a PMSM adapted to a real WP application.
\end{abstract}

Index Terms-Permanent magnet machines, water pumps, design optimization, hydraulic applications, optimal design, magnetic loss, finite element method.

\section{NOMENCLATURE}

$\begin{array}{ll}B_{x y} & \text { Magnetic flux density [T] } \\ D_{i r} & \text { Inner diameter of the rotor [m] } \\ D_{i s} & \text { Inner diameter of the stator [m] } \\ D_{o r} & \text { Outer diameter of the rotor [m] } \\ D_{o s} & \text { Outer diameter of the stator [m] } \\ f_{o b j} & \text { Objective function [-] } \\ g & \text { Air gap length [m] } \\ h_{P M} & \text { Permanent magnet height [m] } \\ h_{s y} & \text { Height of the stator yoke [m] } \\ h_{t} & \text { Height of the tooth [m] } \\ H_{p u m p} & \left.\text { Pump pressure [mH } \mathrm{m}_{2} \mathrm{O}\right] \\ I_{m a x} & \text { Maximum stator current [ARMs] } \\ L & \text { Length of the stack laminations [m] } \\ L_{d} & \text { Inductance in the direct axis }[\mathrm{H}] \\ L_{q} & \text { Inductance in the quadrature axis }[\mathrm{H}] \\ m & \text { Phases number [-] } \\ n & \text { Rotor angular speed [1/min] } \\ N_{p h} & \text { Turns per phase [-] } \\ p & \text { Pairs of poles [-] }\end{array}$

The authors would like to thank the support of the Generalitat de Catalunya under the Industrial Doctorate 2018 DI 004 and 2017SGR0967 projects.

C. Candelo, J. Riba and A. Garcia are with the Electrical Engineering Department, Universitat Politècnica de Catalunya, Barcelona 08034, Spain (e-

\begin{tabular}{|c|c|}
\hline$P_{C u}$ & Copper losses [W] \\
\hline$P_{\mathrm{Fe}}$ & Iron losses [W] \\
\hline$P_{m l}$ & Mechanical losses [W] \\
\hline$P_{\text {pump }}$ & Pump input power [W] \\
\hline$q$ & Slots per pole and phase [-] \\
\hline$Q_{\text {pump }}$ & Volumetric flow rate $[\mathrm{L} / \mathrm{h}]$ \\
\hline$R_{F e}$ & Resistance of the iron $[\Omega]$ \\
\hline$R_{s}$ & Resistance of the stator windings per phase $[\Omega]$ \\
\hline$T$ & Output mechanical torque $[\mathrm{N} \cdot \mathrm{m}]$ \\
\hline$U_{d c}$ & Voltage of the DC bus [V] \\
\hline$w_{P M}$ & Width of the permanent magnets [m] \\
\hline$w_{t}$ & Width of the stator tooth [m] \\
\hline$\eta$ & Energy efficiency [p.u] \\
\hline$\eta_{\text {pump }}$ & Pump efficiency [p.u] \\
\hline$\theta_{e}$ & Electrical angular position [rad] \\
\hline$\theta_{m}$ & Mechanical angular position [rad] \\
\hline$\omega_{m}$ & Electrical angular speed $[\mathrm{rad} / \mathrm{s}]$ \\
\hline$\tau_{s}$ & Slot pitch angle $[\mathrm{rad}]$ \\
\hline$\Psi_{a b c}$ & Flux linkage in the stator $[\mathrm{V} \cdot \mathrm{s}]$ \\
\hline$\Psi_{P M}$ & Flux linkage of the permanent magnets $[\mathrm{V} \cdot \mathrm{s}]$ \\
\hline$\Psi_{s d}$ & Flux linkage in the direct axis $[\mathrm{V} \cdot \mathrm{s}]$ \\
\hline$\Psi_{s q}$ & Flux linkage in the quadrature axis $[\mathrm{V} \cdot \mathrm{s}]$ \\
\hline
\end{tabular}

\section{INTRODUCTION}

$\mathrm{D}$ IFFERENT applications related to water pumps are progressively demanding reduction of size to provide compact designs while offering multiple operational capability [1]. Focusing on the motoring part, permanent magnet synchronous machines (PMSMs) have become the most suitable choice to accomplish these characteristics due their superior capabilities [2], [3].

Focusing on the motor topology choice, some earlier studies compare the suitability of applying PMSMs to actuate submersible pumps instead of applying induction motors (IMs) [4]. The results presented in [4] show that by using PMSMs instead of IMs, power savings of around $20 \%$ are possible. Posterior works show the feasibility of applying autonomous solar powered water pumping systems based on PMSMs, thus reducing economic costs and system complexity [5]. In [6] an uninterrupted standalone solar water pumping system operated with PMSMs is proposed. Other authors focus on improving the control of the PMSM specifically for water pumping applications. In [7], a PMSM sensorless speed drive for singlestage photovoltaic (PV) water pumping applications is presented, which allows eliminating the current sensors, thus reducing installation costs. Other studies as [8] focus on improving the PMSM drive by proposing a fuzzy pre-

mail: carlos.andres.candelo@upc.edu; jordi.riba-ruiz@upc.edu; antoni.garcia@upc.edu).

P. Tubert is with the mechanical engineering department, Midtal Talentos S.L, Banyoles 17820, Spain (e-mail: pere.tubert@midtal.net). 
compensated hybrid proportional integral (PI) controller, which offers improved parameter sensitivity compared to conventional PI controllers with constant parameters. Despite new contributions in this field, there is a lack of works focusing on the PMSM design for water pumping applications, this paper contributes in this area.

Focusing on the optimal design of PMSMs using FEA, some earlier studies couple optimization algorithms with timedependent finite element method to increase PMSM efficiency [9]. Nevertheless, due to the high computational burden required by time dependent FEA, different studies restricted the number of analyzed operational points [10]-[12], whereas other studies [13], [14] limited the number of variables to be optimized. The computational burden can be greatly reduced by applying magneto-static FEA. In [15] the space-time transformation is applied jointly with a magneto-static computation approach to improve the overall accuracy. Other studies as [16] use the so called computationally-efficient FEA (CE-FEA), which uses the pseudo rotating position to reproduce the time evolution of electromagnetic magnitudes using magneto-static analysis. Some other studies avoid using FEA by applying supervised machine learning [17] . Nevertheless, these methods are limited to the PMSM topology of study, while depending on an analytical model to perform the electromagnetic [18] or a thermal analysis [19].

Regarding PMSM design optimization focused on pump applications, [20] designs a low voltage (12 Vdc) PM motor for electric transmission oil pump applications, whereas the authors of [21] design a high power surface mounted PMSM for a directly coupled pump application using time-dependent FEA.

This study develops a methodology to design and optimize PMSMs by defining the desired torque-speed-efficiency map adapting its performance to the WP hydraulic characteristics. The designer has plenty of freedom to define the efficiency levels and distribution along the torque-speed-map including the losses distribution and power rating. Thus, once the hydraulic efficiency is known, the approach presented in this paper offers the designer plenty of freedom to customize the design of the PMSM by defining the target efficiency map in the torque-speed plane, while ensuring the desired performance of the WP-PMSM system. This methodology uses ultra-fast finite element analysis (UF-FEA) by applying magneto-static computations together with a time-space conversion to compute the iron losses. It allows a great reduction of the computational resources and performing the design-optimization in an affordable time frame, while allowing to increase the number of variables to be optimized. The model considers the iron losses by using a time-space transformation together with pseudo rotating analysis, thus being possible to determine the magnetic flux density harmonic content using FEA. The torquespeed-efficiency map is calculated by applying a directquadrature $(d-q)$ electrical model. The process designs the PMSM by adapting its performance to the predefined control strategy. For the same geometry it is possible to analyze the performance based on different control strategies, i.e., maximum torque per ampere (MTPA), maximum torque per volt (MTPV), maximum efficiency (ME), flux weakening (FW). The objective function uses a novel image comparison technique, the structural similarity index (SSIM), which allows comparing the similarity of two torque-speed-efficiency maps.
Finally, the proposed methodology is validated experimentally by designing and testing a PMSM adapted to a real WP.

The paper is organized as follows. Section II details the PMSM-WP design methodology. Section III performs an experimental validation. Finally, Section IV concludes the paper.

\section{PMSM-WP Design Methodology}

This section introduces the PMSM design process focusing on WP applications. The methodology is divided in five steps, which are detailed in Fig. 1. First, starting from the hydraulics characteristics, i.e., water pump (WP) efficiency $\left(\eta_{\text {pump }}\right)$, pressure $\left(H_{\text {pump }}\right)$ and shaft power required by the pump $\left(P_{\text {pump }}\right)$, the WP torque-speed-efficiency map is calculated. This transformation allows to convert hydraulics characteristics into the torque-speed plane, thus obtaining the PMSM demands. Once they are known, the design strategy starts by defining the desired PMSM torque-speed-efficiency map. This efficiency distribution is customized by the designer based on the required PMSM performance to achieve a given WP-PMSM system efficiency in a selected torque-speed area.

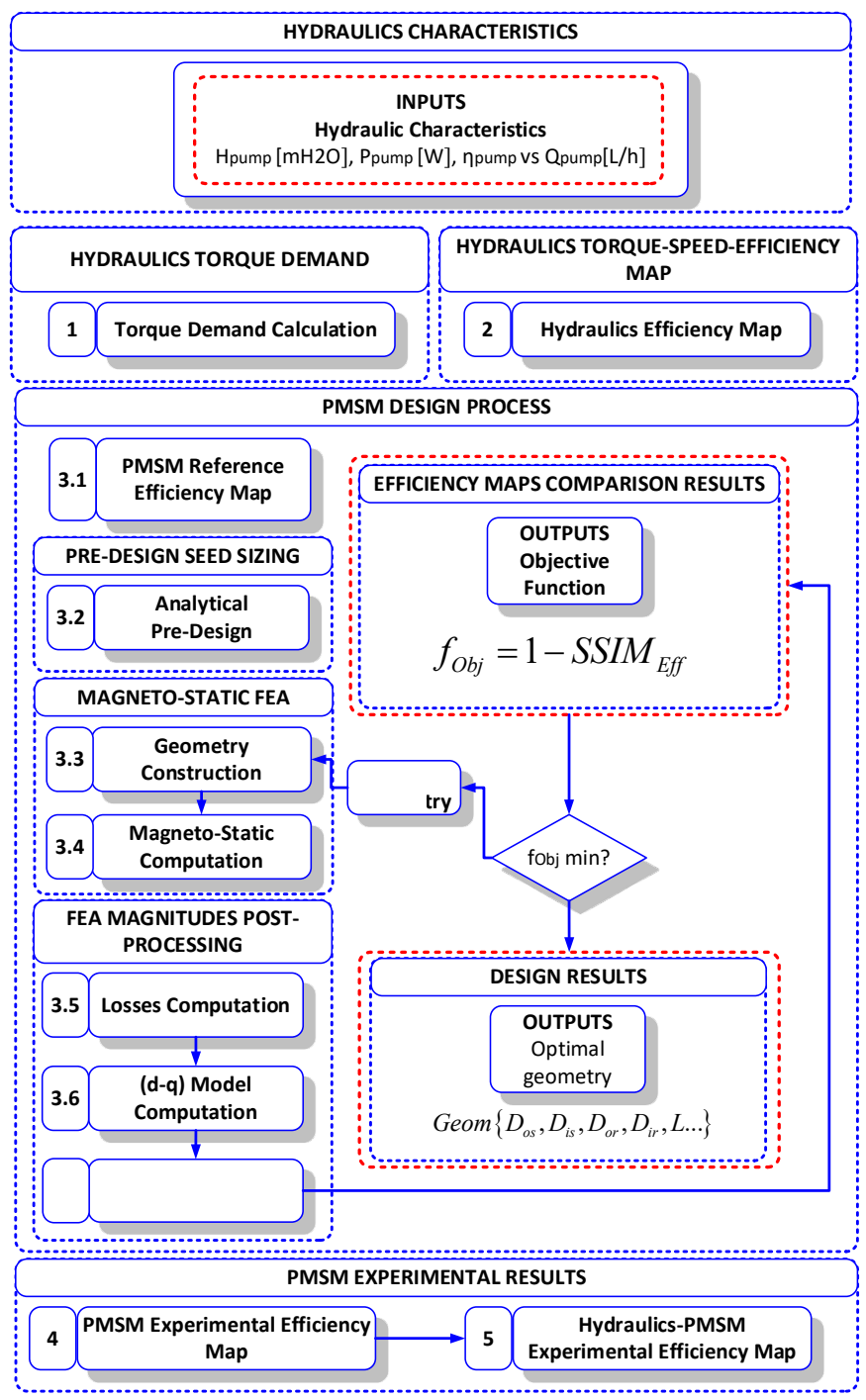

Fig. 1. PMSM-WP design methodology. 
The PMSM rated characteristics, power envelope and losses distribution are defined at the very initial stage of the sizing process.

The objective of this customization is to provide the designer with plenty of freedom to design the PMSM characteristics according to the requirements of the hydraulic application. The customization can be applied either when some specific WP working points for a given application are known, or when selecting a range of working points in order to design a PMSM for different applications. Finally, the PMSM is sized according to the torque-speed-efficiency map defined at the very initial stage of the process.

Fig. 2 shows the PMSM-WP system.

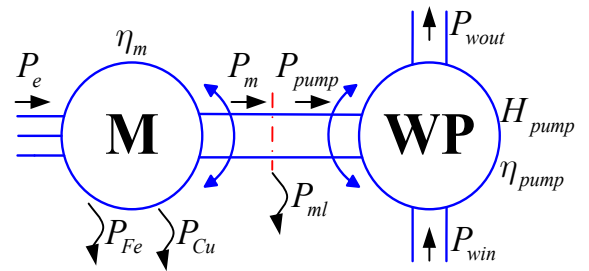

Fig. 2. PMSM-WP system.

\section{A. WP Hydraulic Characteristics, Torque Demand and Torque-Speed-Efficiency Map Calculation}

The process starts with the hydraulic characteristics [22], i.e., the efficiency $\left(\eta_{\text {pump }}\right)$, pressure $\left(H_{\text {pump }}\right)$ and power $\left(P_{\text {pump }}\right)$ over the volumetric flow rate $\left(Q_{\text {pump }}\right)$ for different angular speeds, as shown in Fig. 3. The angular speed range must include the minimum and maximum allowable values to have full information of the operational range of the hydraulic system.

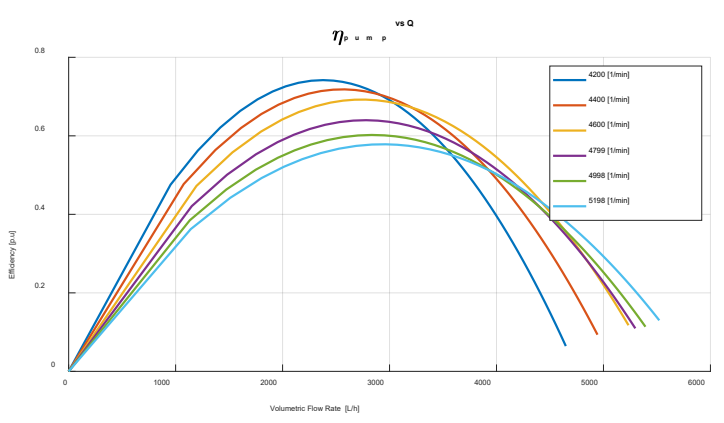

(a)

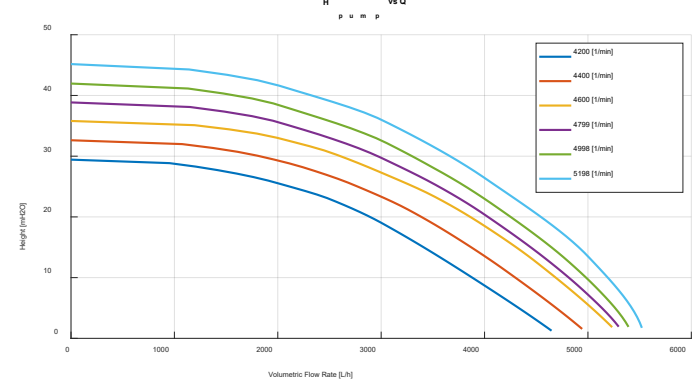

(b)

From the power required by the pump $\left(P_{\text {pump }}\right)$ for every angular speed $n$, the torque demand can be calculated for all analyzed points as,

$T_{\text {pump }}\left(Q_{\text {pump }}, n\right)=\frac{P_{\text {pump }}\left(Q_{\text {pump }}, n\right)}{n}$

Once the torque demand is known for all operational points $T_{\text {pump }}\left(Q_{\text {pump }}, n\right)$ and the associated hydraulic efficiency $\eta_{\text {pump }}\left(Q_{\text {pump }}, n\right)$, these magnitudes can be rearranged to express the hydraulic efficiency as a function of the torque and rotational speed $\eta_{\text {pump }}\left(n, T_{\text {pump }}\right)$.

$$
T_{\text {pump }}\left(Q_{\text {pump }}, n\right), \eta_{\text {pump }}\left(Q_{\text {pump }}, n\right) \rightarrow \eta_{\text {pump }}\left(n, T_{\text {pump }}\right)
$$

Fig. 4 shows the WP torque-speed operation area. After applying the conversion in (2), the superior and inferior envelopes define, respectively, the maximum and minimum torque demanded by the WP at any rotational speed.

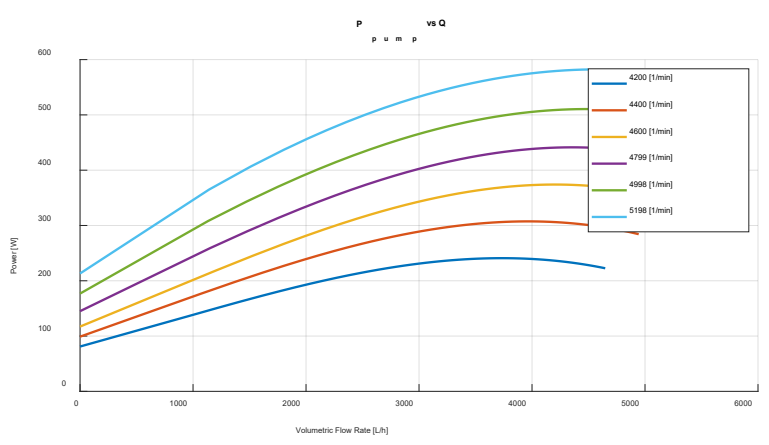

(c)

Fig. 3. Water Pump hydraulic characteristics (a) Efficiency over volumetric flow. (b) Height pressure over volumetric flow. (c) Hydraulic power over volumetric flow.

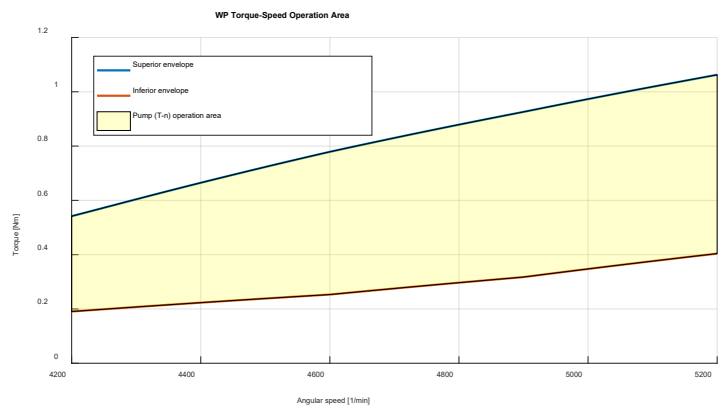

Fig. 4. WP torque-speed operation area.

Fig. 5 shows the experimental WP torque-speed-efficiency map. Once this map is known, the designer is able to select an area of interest. By knowing the WP efficiency characteristics, it is possible to impose the PMSM efficiency before starting the design process. This ensures the required system efficiency for the selected application.

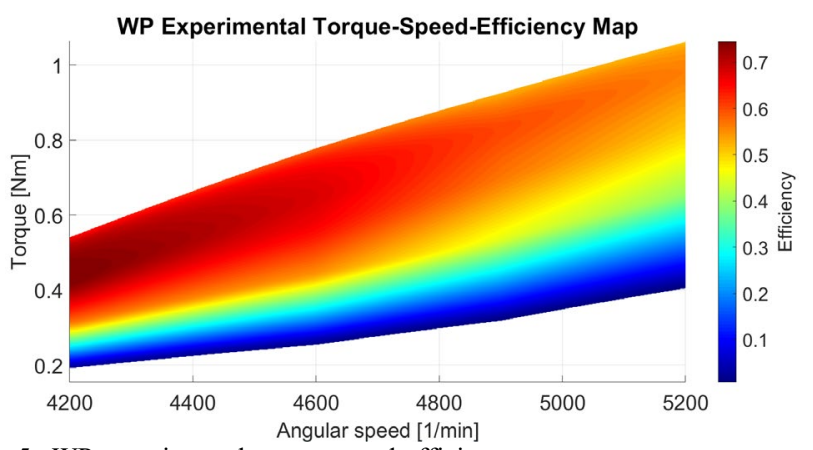

Fig. 5. WP experimental torque-speed-efficiency map.

\section{B. PMSM Design Process}

This subsection details the PMSM-WP design-optimization process used to size the PMSM from the reference torquespeed-efficiency map defined by the designer. More details can be found in [23]. It is noted that in this paper we apply the same principle than in [23] but widening the design scope, since 
instead of starting with an already existing PMSM, this paper starts the process from the specifications of a hydraulic application an adapting the PMSM torque-speed-map to the desired system performance. The proposed process is divided in seven steps, from 3.1 to 3.7 as summarized in Fig. 1. Step 3.1 defines the target torque-speed-efficiency map. This first step is of major importance because the designer sets the desired motor performance along the torque-speed plane. After this, the geometry of an initial PMSM is calculated by means of analytical equations (step 3.2). The aim is to provide a seed geometry to start the optimization process. Once the seed geometry is introduced, a magneto-static electromagnetic analysis is performed (steps 3.3 and 3.4). Motor losses are obtained from the whole available data (3.5), and next, the torque-speed-efficiency map is computed using a $d-q$ circuit model (3.6 and 3.7 in Fig. 1). This map is compared with the reference efficiency map settled at the beginning of the design process. To perform this comparison, the structural similarity index SSIM [24] is applied and the objective function is computed. This index calculates the similarity degree between two different matrices, in this case two torque-speed-efficiency maps. SSIM returns a normalized output within 0 and 1 , the minimum and maximum similarities between two maps. The optimization algorithm minimizes the objective function $f=1$ SSIM by changing the geometrical parameters at each iteration.

\section{1) PMSM Reference Torque-Speed-Efficiency Map}

First, an initial PMSM reference torque-speed-efficiency map is defined. This step is aimed to provide the required motor performance for the application. The designer has full freedom of defining the efficiency levels and its distribution along the torque-speed map. Within this definition is included implicitly the losses distribution and the power rating. This step is the more relevant in the whole design-optimization process due the PMSM to be design depends strictly on the efficiency map defined. The algorithm will achieve the motor characteristics which adjust a much as possible to this defined performance.

\section{2) Analytical Pre-Design and Geometry Construction}

Once the initial torque-speed-efficiency map is defined, an initial or seed geometry is needed to start the designoptimization process. This initial geometry is obtained by applying analytical equations and some design rules which ensure a solution nearby the optimum [25], [26]. Table I shows the geometric parameters dealt with in the optimization stage.

TABLE I

GEOMETRIC PARAMETERS TO OPTIMIZE

\begin{tabular}{c|c}
\hline \hline Parameters & Information \\
\hline$d_{\text {wire }}$ & Diameter of the conductors [m] \\
\hline$D_{i r}$ & Inner diameter of the rotor [m] \\
\hline$D_{i s}$ & Inner diameter of the stator [m] \\
\hline$D_{o r}$ & Outer diameter of the rotor [m] \\
\hline$D_{o s}$ & Outer diameter of the stator [m] \\
\hline$g$ & Length of the air gap [m] \\
\hline$h_{b r g}$ & Height of the bridges in the rotor [m] \\
\hline$h_{P M}$ & Height of the permanent magnets [m] \\
\hline$h_{r i b}$ & Height of the rotor ribs [m] \\
\hline$h_{s o}$ & Height of the slots opening [m] \\
\hline$h_{s y}$ & Height of the stator yoke [m] \\
\hline$h_{t}$ & Height of the tooth [m] \\
\hline$L$ & Length of the stack laminations [m] \\
\hline$N_{p h}$ & Turns per phase [-] \\
\hline$w_{b r g}$ & Width of the rotor bridges [m] \\
\hline \hline
\end{tabular}

\begin{tabular}{c|c}
\hline \hline$w_{P M}$ & Width of the permanent magnets [m] \\
\hline$w_{s o}$ & Width of the slot openings [m] \\
\hline$w_{t}$ & Width of the tooth [m] \\
\hline$w_{w e b}$ & Width of the rotor web [m] \\
\hline \hline
\end{tabular}

A total number of 19 parameters are optimized. Because some equality and inequality rules are defined (see Table II), the number of parameters are reduced to 16 .

TABLE II

PMSM GEOMETRICAL RULES

\begin{tabular}{|c|c|}
\hline \multicolumn{2}{|c|}{ Linear Equality Rules } \\
\hline $\begin{array}{l}\text { The inner stator } \\
\text { diameter must be equal } \\
\text { to the outer rotor } \\
\text { diameter plus two times } \\
\text { the airgap length }\end{array}$ & $D_{o r}+2 \cdot g=D_{i s}$ \\
\hline $\begin{array}{l}\text { The inner stator } \\
\text { diameter plus two times } \\
\text { the tooth height plus two } \\
\text { times the stator yoke } \\
\text { height must be equal to } \\
\text { the outer stator diameter }\end{array}$ & $D_{i s}+2 \cdot h_{t}+2 \cdot h_{s y}=D_{o s}$ \\
\hline \multicolumn{2}{|c|}{ Linear Inequality Rules } \\
\hline $\begin{array}{l}\text { The outer rotor diameter } \\
\text { has to be always bigger } \\
\text { than the inner rotor } \\
\text { diameter. }\end{array}$ & $D_{o r}>D_{i r}$ \\
\hline $\begin{array}{l}\text { The outer stator } \\
\text { diameter has to be } \\
\text { always bigger than the } \\
\text { inner stator diameter. }\end{array}$ & $D_{o s}>D_{i s}$ \\
\hline $\begin{array}{l}\text { The height of the stator } \\
\text { tooth is bigger than the } \\
\text { slot opening height. }\end{array}$ & $h_{t}>h_{s o}$ \\
\hline $\begin{array}{l}\text { The rotor bridge and rib } \\
\text { height will never be } \\
\text { smaller than } 0.5 \mathrm{~mm} \text { to } \\
\text { guarantee physical } \\
\text { robustness. }\end{array}$ & $\begin{aligned} 1 \mathrm{~mm} & \geq h_{b r g} \geq 0.5 \mathrm{~mm} \\
1 \mathrm{~mm} & \geq h_{r i b} \geq 0.5 \mathrm{~mm}\end{aligned}$ \\
\hline $\begin{array}{l}\text { Stack length } \mathrm{L} \text { has to be } \\
\text { greater than zero and } \\
\text { always as maximum as } \\
\mathrm{D}_{\text {os. }}\end{array}$ & $0<L \leq D_{o s}$ \\
\hline
\end{tabular}

\section{Non-Linear Equality Rules}

The permanent magnet width plus the rib height plus the rotor bridges projected in the same line have to be equal than the projection of the pith arc.

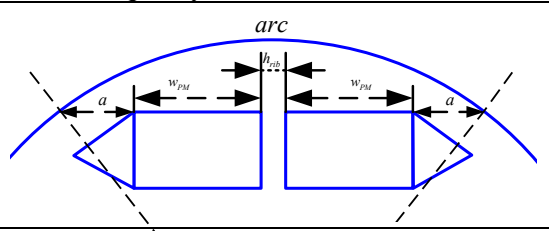

Non-Linear Inequality Rules

The stator tooth width has to be always smaller than slot pith arc projected in the line. The values are taken for the mid-height of the tooth.

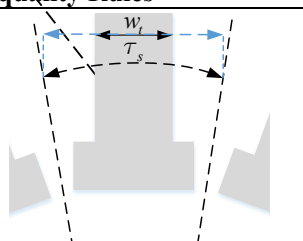

The ratio between the wire section taking into account the isolation times the number of wires corresponding per slot over the total slot section has to be less or equal than 0.5

Once the geometric parameters summarized in Table I are obtained, either the seed/initial geometry or the geometry found during the iterative optimization stage, it is necessary to evaluate the correctness and feasibility of the geometry dealt with. Once checked, the geometry is built into the FEA environment. 
Table III shows the materials used in the PMSM. The $B-H$ curve of the laminations is included in the COMSOL Multiphysics ${ }^{\circledR}$ FEA software.

TABLE III

PMSM MATERIALS

\begin{tabular}{c|c}
\hline \hline Stator laminations & M400-50A \\
\hline Rotor laminations & M400-50A \\
\hline Permanent magnets & Nd35H \\
\hline Winding & Copper \\
\hline \hline
\end{tabular}

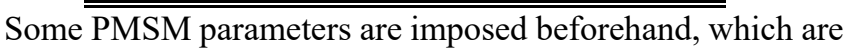
chosen in terms of manufacturing reliability and simplicity. These parameters are exposed in Table IV.

TABLE IV

PMSM FIXED PARAMETERS

\begin{tabular}{c|c}
\hline \hline Number of pole pairs & 3 \\
\hline Number of stator slots & 9 \\
\hline Winding typology & Concentrated \\
\hline Number of layers & 2 \\
\hline Rotor topology & Interior PMSM \\
\hline \hline
\end{tabular}

3) Magneto-Static Computation and Losses Computation

After introducing the geometry into the FEA environment, a magneto-static FEA study is carried out using COMSOL Multiphysics ${ }^{\circledR}$ package. This study consists in analyzing certain static electromagnetic conditions to obtain relevant electromagnetic information. To this end, a suitable discretization is required, which is performed as follows. First, the positive rotor $d$-axis (direction to which the permanent magnets flux points radially outwards) aligns with the phase $a$, the phase taken as the reference. Then, the space vector defining the current is injected in the negative direct axis direction. A magneto-static FEA simulation is performed taking into account the present electromagnetic conditions. This same procedure is repeated by changing the current space vector $\left(i_{s}, \theta_{e}\right)$ and rotor position $\theta_{m}$. The outputs of this computation are the stator flux linkage in the $d-q$ frame, the internal torque over the injected current vector, and the magnetic flux density spatial distribution. The flux linkage of the three phases and the electromagnetic torque are obtained directly from the FEA software (COMSOL Multiphysics $\left.{ }^{\circledR}\right)$. These variables are used to determine the characteristics of the PMSM characteristics by means of a $d-q$ model. Fig. 6 shows the rotor position angle $\theta_{m}$ and the current space vector $\left(i_{s}, \theta_{e}\right)$.

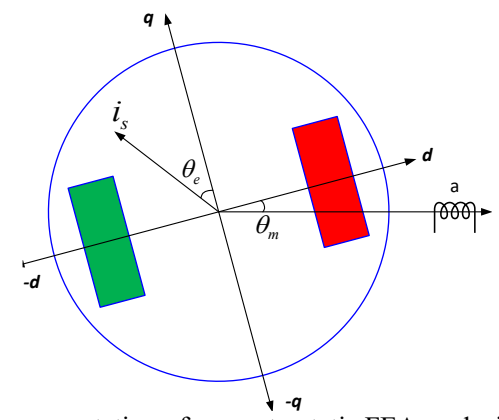

Fig. 6. Generic representation of magneto-static FEA analysis disposition.

One of the most difficult aspects when studying PMSM using magneto-static FEA is to determine the steady state performance for all computation points. Thus, to find the voltages, currents, efficiency, power factor, etc., the calculation of the power losses is the weakest point, since it is strictly dependent on the time domain study. The considered losses are those generated in the copper resistance, magnetic laminations and the mechanical losses of the entire drive system. Losses are explained in detail in this subsection. To compute the copper losses, it is necessary to know the windings phase resistance. FEA software provides a fast way to calculate this parameter. As the process is designed to be a fast tool, the effect of the temperature is not considered, but the estimated copper temperature can be specified beforehand by the designer, which can be adapted depending on the required application.

Fig. 7 synthetizes the magneto-static analysis process.

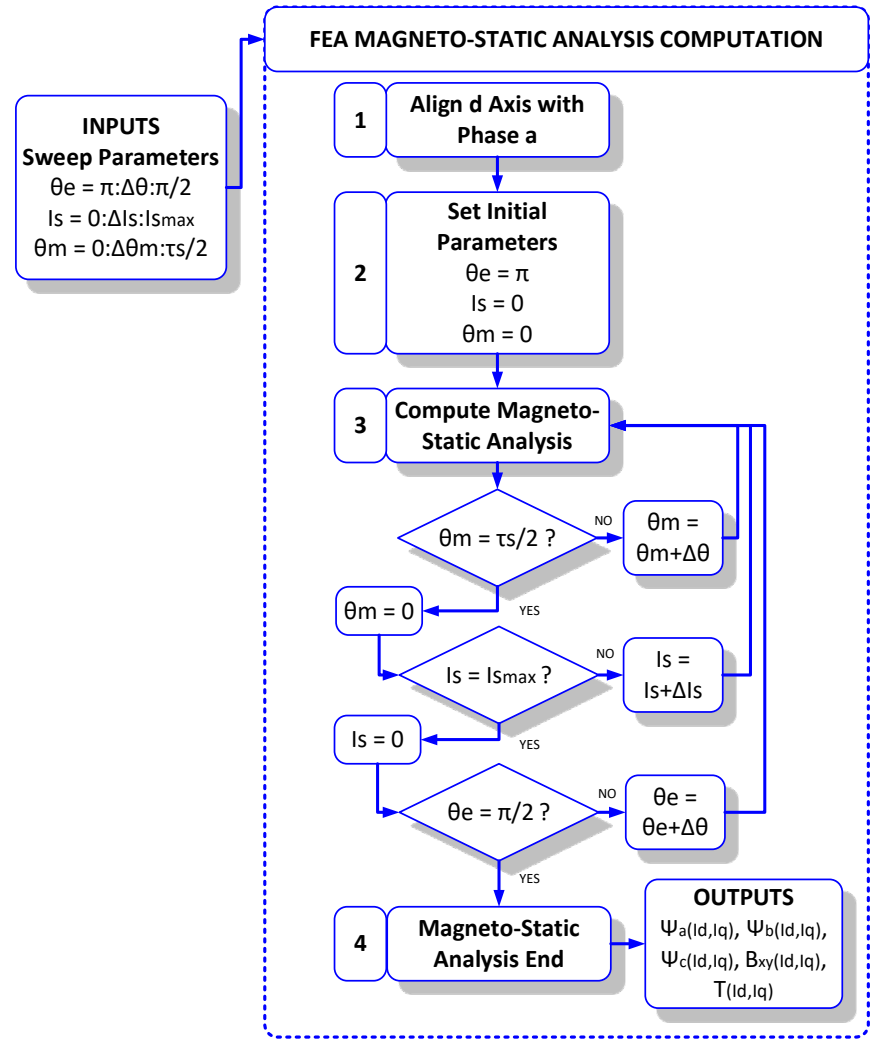

Fig. 7. Magneto-Static Algorithm computation.

The calculation of the iron or magnetic losses using magnetostatic FEA is the most challenging step of the designoptimization procedure. Time-dependent Bertotti equations are used for this purpose. Since the proposed algorithm uses a magneto-static approach, this paper proposes a new methodology to compute the magnetic losses. The method considers the magnetic flux density spatial distribution to determine the change of such magnitude over time.

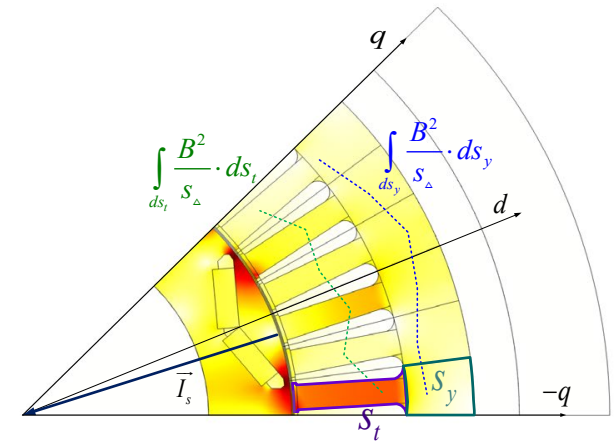

Fig. 8. Generic example of the spatial magnetic flux density distribution analyzed in the regions of interest. 
To analyze the magnetic flux density distribution, two regions are defined, i.e., the stator yoke and tooth (Fig. 8). The flux density spatial distribution is analyzed in all defined regions. The flux density spatial distribution along the stator is obtained from the magnetic flux density of all teeth. By applying the time-space conversion in (3), a time-dependent wave is obtained. Next, the flux density spatial distribution wave is decomposed in harmonic components in order to compute the Bertotti equations.

$$
\left(\frac{d B}{d \theta_{e}}\right)=\left(\frac{d B}{d t}\right) \cdot\left(\frac{d t}{d \theta_{e}}\right) \rightarrow\left(\frac{d B}{d t}\right)=\left(\frac{d B}{d \theta_{e}}\right) \cdot \omega_{m}
$$

By applying the time-space conversion, the Bertotti equations for every finite region result as,

$$
\begin{aligned}
& P_{F e-H y s t}=\frac{K_{h} \cdot \rho}{T} \cdot \int_{d \forall} B_{m}{ }^{\alpha} \cdot\left(1+\sum_{i=1}^{n} \frac{\beta}{B_{m}} \cdot\left(\Delta B_{i}\right)\right) \cdot d \forall \\
& P_{F e-E d d y}=\frac{\sigma \cdot h^{2}}{12 \cdot T} \cdot \omega_{m}{ }^{2} \cdot \int_{0}^{T} \int_{d \forall}\left(\frac{d B}{d \theta_{e}}\right)^{2} \cdot d \forall \cdot d \theta_{e} \\
& P_{F e-\text { Excess }}=\frac{K_{e x c} \cdot \rho}{T} \cdot \omega_{m}{ }^{1.5} \cdot \int_{0}^{T} \int_{d \forall}\left(\left|\frac{d B}{d \theta_{e}}\right|\right)^{1.5} \cdot d \forall \cdot d \theta_{e}
\end{aligned}
$$

$\sigma$ being the electrical conductivity, $d \forall$ the differential volume, $h$ the iron laminations thicknes, $\rho$ the mass per unit volume, $K_{h}$ the hysteresis constant, $T$ the time period, $\alpha$ the hysteresis exponent, $\beta$ the minor loop constant, and $K_{\text {exc }}$ the excess constant.

The mechanical losses considered in this model are mainly due to the bearings and rotor. These losses are considered in an external model [27].

\section{4) $d-q$ Model Computation}

The $d-q$ model of the PMSM is used to calculate its performance over the whole torque-speed plane. The model is considered under the quasi-static hypothesis [28]. The advantage of using this model is the possibility of computing the operating characteristics considering the control strategy.

From the magneto-static computation, the flux linkage over the current in the $d-q$ frame can be obtained (7). If the flux linkage is known, it is possible to compute the backelectromotive force (BEMF), which depends on the electrical angular speed (8).
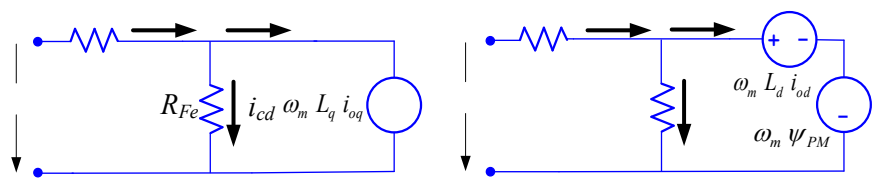

Fig. 9. $d-q$ model of the PMSM

When computing the electrical model considering the control strategy, the currents $i_{o d}$ and $i_{o q}$ are selected as a function of the applied control strategy, i.e., maximum torque per ampere MTPA, maximum efficiency ME, maximum torque per volt MTPV, etc. As observed in the circuit representation, the iron losses are modelled through a parallel resistance. This resistance changes with the current injection, by taking into account the iron saturation and the stator frequency. The iron resistance is computed as in (9). The current consumed by the iron resistance in the $d-q$ frame, i.e., $i_{c d}$ and $i_{c q}$ are computed.
Once obtained the current consumed by the iron resistance and the required by the torque demand, the total currents in each axis are computed, i.e., $i_{d}$ and $i_{q}$. Finally, the $d-q$ voltages under the quasi-static hypothesis, are defined as in (10).

$$
\begin{aligned}
& \left\{\begin{array}{l}
\psi_{d}=\psi_{P M}+L_{d}\left(i_{d}, i_{q}\right) \cdot i_{o d} \\
\psi_{q}=L_{q}\left(i_{d}, i_{q}\right) \cdot i_{o q}
\end{array}\right. \\
& \left\{\begin{array}{l}
u_{o d}=-\omega_{e} \cdot L_{q}\left(i_{d}, i_{q}\right) \cdot i_{o q}=-\psi_{q} \cdot \omega_{e} \\
u_{o q}=\omega_{e} \cdot\left(L_{d}\left(i_{d}, i_{q}\right) \cdot i_{o d}+\psi_{P M}\right)=\psi_{d} \cdot \omega_{e}
\end{array}\right. \\
& R_{F e}=m \cdot\left(u_{o d}{ }^{2}+u_{o q}{ }^{2}\right) /\left(2 \cdot P_{F e}\right) \\
& \left\{\begin{array}{l}
u_{d}=R_{s} \cdot i_{d}+L_{d}\left(i_{d}, i_{q}\right) \cdot \frac{d}{d t} \cdot i_{o d}-\omega_{e} \cdot L_{q}\left(i_{d}, i_{q}\right) \cdot i_{o q} \\
u_{q}=R_{s} \cdot i_{q}+L_{q}\left(i_{d}, i_{q}\right) \cdot \frac{d}{d t} \cdot i_{o q}+\omega_{e} \cdot L_{d}\left(i_{d}, i_{q}\right) \cdot i_{o d}+\omega_{e} \cdot \Psi_{P M}
\end{array}\right.
\end{aligned}
$$

Fig. 10 synthetizes the algorithm to compute the operational points using the $d-q$ model and the posterior selection of the current space vector selection based on the applied control law.

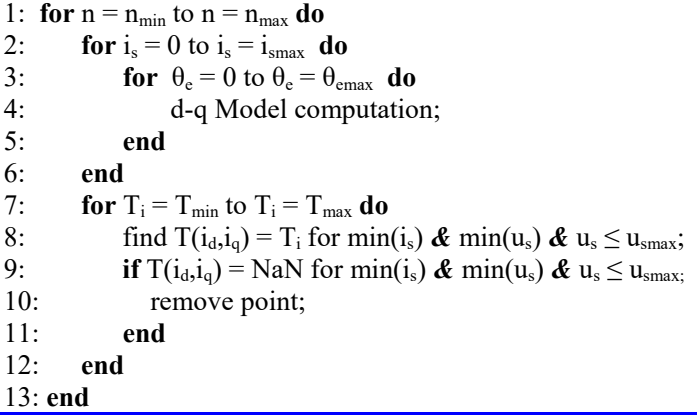

Fig. 10. $d-q$ model computation algorithm and current space vector selection considering MTPA and FW control strategies.

As can be seen in Fig. 10, a main loop with the discretized angular speed is designed. This loop first computes all possible operational points using the $d-q$ electrical model. Next, the current magnitude and angles are selected for each discrete torque according to the selected control law.

\section{5) PMSM Model and Efficiency Maps Comparison with SSIM indicator}

Once the $d-q$ electrical model has been computed, the PMSM efficiency map can be obtained as well as the characteristics of the current geometry. Once the torque-speed-efficiency map has been obtained by means of the $d-q$ model, it is compared with the reference torque-speed-efficiency map by using the structural similarity index SSIM. This index provides the similarity degree between two matrices, returning a value in the $[0,1]$ interval. The SSIM calculates three main features, the overall standard deviation, the point-to-point relative difference, and the structural similarity between different points contained in the matrix. SSIM provides information about the similarity between the efficiency distribution of the designed and the objective PMSMs. The goal is to minimize the objective function $f=1$-SSIM. The optimization solver changes the geometrical parameters to minimize the objective function. The pattern search optimization solver from Matlab ${ }^{\circledR}$ was applied to this end. This direct search method is used due its superior capabilities over other optimization methods [29], [30]. 
6) Structural Similarity Index SSIM

The SSIM discerns three main aspects: intensity, standard deviation and data structure. Each of these aspects are aimed at providing a different type of information of the similarity between two images or matrices. The mean value of matrix $x$ is defined as,

$\mu_{x}=\frac{1}{N} \cdot \sum_{i=1}^{N i} \sum_{j=1}^{N j} x_{i j}$

$N=N_{i} \cdot N_{j}$ being the total number of components of the matrix and $x_{i j}$ the $(i, j)$ component of the matrix.

The intensity is defined as,

$$
l(x, y)=\frac{2 \cdot \mu_{x} \cdot \mu_{y}+C_{1}}{\mu_{x}^{2}+\mu_{y}^{2}+C_{1}}
$$

$x$ and $y$ being the matrices to compare and $C_{l}$ a constant used to avoid computational instabilities when $\mu_{x}{ }^{2}+\mu_{y}{ }^{2}$ is close to zero.

The standard deviation is defined as,

$$
\sigma_{x}=\left(\frac{1}{N-1} \cdot \sum_{i=1}^{N_{i}} \sum_{j=1}^{N_{j}}\left(x_{i j}-\mu_{x}\right)^{2}\right)^{\frac{1}{2}}
$$

Therefore, the comparison between the standard deviation of the matrices is as follows,

$$
c(x, y)=\frac{2 \cdot \sigma_{x} \cdot \sigma_{y}+C_{2}}{\sigma_{x}^{2}+\sigma_{y}{ }^{2}+C_{2}}
$$

Third evaluation compares normalized matrices to analyze the structure of the data, defined as follows,

$s(x, y)=\frac{\sigma_{x y}+C_{3}}{\sigma_{x} \cdot \sigma_{y}+C_{3}}$

Where $\sigma_{x y}$ is the correlation coefficient between matrices.

$\sigma_{x y}=\frac{1}{N-1} \cdot \sum_{i=1}^{N i} \sum_{j=1}^{N j}\left(x_{i j}-\mu_{x}\right) \cdot\left(y_{i j}-\mu_{y}\right)$

Finally, SSIM results in,

$\operatorname{SSIM}=l(x, y) \cdot c(x, y) \cdot s(x, y)$

\section{Design Results}

Analogously, once the PMSM design-optimization process has been performed, the PMSM geometry is obtained.

Once performed the PMSM-WP design-optimization process, the PMSM is manufactured and tested. The objective is to represent the experimental torque-speed-efficiency map in order to have the real PMSM-WP torque-speed-efficiency map, as well as to experimentally validate the design process.

Once the PMSM has been tested and validated, the motor torque-speed-efficiency map can be used to determine the system torque-speed-efficiency map.

\section{RESULTS}

To validate the design-optimization algorithm a PMSM is designed for a specifically hydraulic application.

\section{A. Hydraulic Torque-Speed-Efficiency Map}

Fig. 11 shows the experimental hydraulic torque-speedefficiency map of the water pump application.

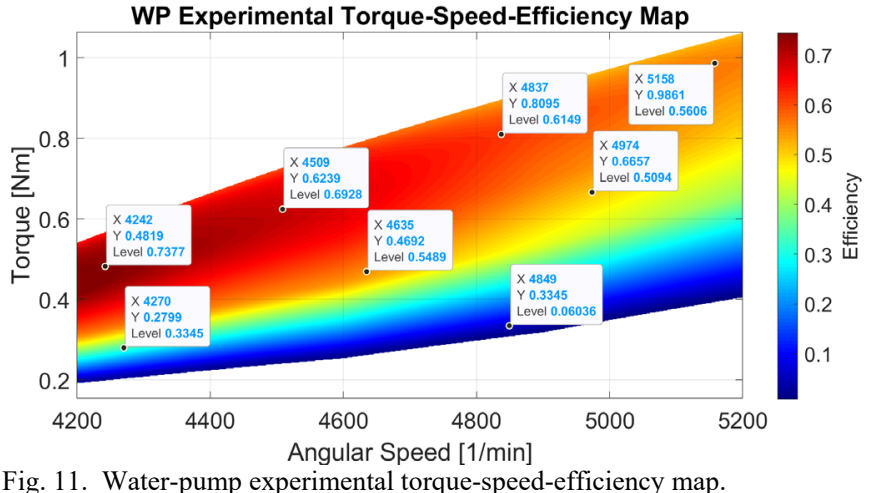

Fig. 11. Water-pump experimental torque-speed-efficiency map.

Table V summarizes some selected operational points of the water pump efficiency map, which are highlighted in Fig. 11.

TABLE V

WP EFFICIENCY MAP SELECTED OPERATIONAL POINTS

\begin{tabular}{c|c|c}
\hline \hline $\begin{array}{c}\text { Angular velocity } \\
\text { (1/min) }\end{array}$ & Torque (Nm) & $\begin{array}{c}\text { Efficiency } \\
\text { (p.u) }\end{array}$ \\
\hline 4242 & 0.4819 & 0.7377 \\
\hline 4270 & 0.2799 & 0.3345 \\
\hline 4509 & 0.6239 & 0.6928 \\
\hline 4635 & 0.4692 & 0.5489 \\
\hline 4849 & 0.3345 & 0.0603 \\
\hline 4837 & 0.0895 & 0.6149 \\
\hline 4974 & 0.6657 & 0.5094 \\
\hline 5158 & 0.9861 & 0.5606 \\
\hline \hline
\end{tabular}

B. Reference PMSM Torque-Speed-Efficiency Map and Fixed Parameters

Once hydraulic torque-speed-efficiency map is obtained, the PMSM reference efficiency map distribution is designed. In this study, two initial torque-speed-efficiency points of the WPPMSM system were imposed, which were interpolated to obtain five initial points of the desired PMSM torque-speed-efficiency map in order to improve the resolution of this objective map. In Table VI shows the two imposed system efficiencies (bold style) and the interpolated points.

TABLE VI

REFERENCE EFFICIENCY DISTRIBUTION LEVELS

\begin{tabular}{c|c|c|c|c}
\hline \hline $\begin{array}{c}\text { Angular } \\
\text { velocity } \\
(\mathbf{1} / \mathbf{m i n})\end{array}$ & $\begin{array}{c}\text { Torque } \\
\text { (Nm) }\end{array}$ & $\begin{array}{c}\text { System } \\
\text { Efficiency } \\
\text { (p.u) }\end{array}$ & $\begin{array}{c}\text { WP } \\
\text { Efficiency } \\
\text { (p.u) }\end{array}$ & $\begin{array}{c}\text { PMSM } \\
\text { Efficiency } \\
\text { (p.u) }\end{array}$ \\
\hline $\mathbf{5 2 0 0}$ & $\mathbf{1 . 0 6}$ & $\mathbf{0 . 4 3}$ & $\mathbf{0 . 5 1 2}$ & $\mathbf{0 . 8 4}$ \\
\hline 5100 & 1.00 & 0.45 & 0.542 & 0.83 \\
\hline 5000 & 0.90 & 0.48 & 0.578 & 0.83 \\
\hline 4900 & 0.80 & 0.49 & 0.598 & 0.82 \\
\hline $\mathbf{4 7 0 0}$ & $\mathbf{0 . 7 0}$ & $\mathbf{0 . 5 0}$ & $\mathbf{0 . 6 2 6}$ & $\mathbf{0 . 8 0}$ \\
\hline \hline
\end{tabular}

The first requirement is to have a system efficiency of 0.5 at $4700 \mathrm{rpm}$ and $0.7 \mathrm{Nm}$. The second requirement is to accomplish with the IE4 PMSM standard [31] efficiency at $5200 \mathrm{rpm}$ and $1.06 \mathrm{Nm}$, which leads to a system efficiency of 0.43 . The other points are interpolated to have a gradual efficiency change between both operational points. It results in four levels of PMSM efficiency, i.e., $0.84,0.83,0.82$ and 0.80 respectively. In this case. Fig. 12 shows the PMSM reference torque-speedefficiency map according to the points defined in Table VI. 


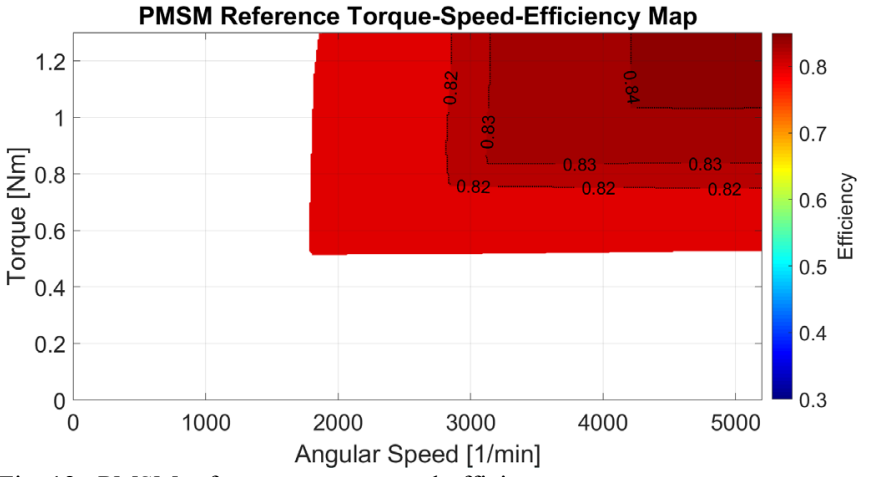

Fig. 12. PMSM reference torque-speed-efficiency map.

For the application, the outer stator diameter is fixed to 90 $\mathrm{mm}$ due to space constraints.

\section{PMSM Torque-Speed-Efficiency Map}

The design-optimization process is applied once the reference torque-speed-efficiency map has been defined. Next, the PMSM geometry is found by means of its correspondent FEA model torque-speed-efficiency map. Once designed, the PMSM is manufactured and tested to experimentally validate the torque-speed-efficiency map. Figs. 13 (a) and 13 (b) show, respectively, the model and experimental PMSM torque-speedefficiency maps.

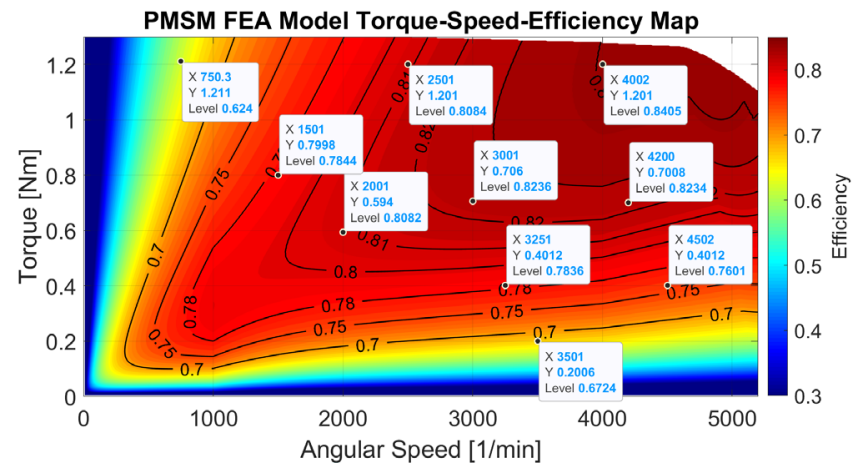

(a)

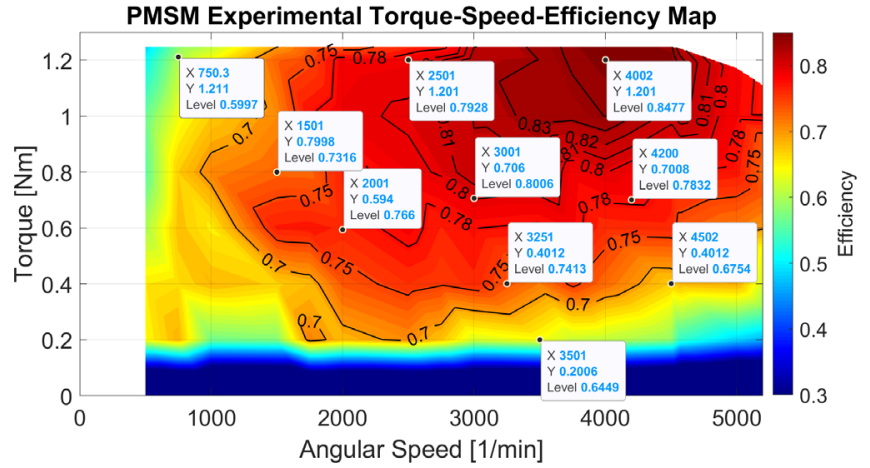

(b)

Fig. 13. (a) PMSM FEA model torque-speed-efficiency map. (b) PMSM experimental torque-speed-efficiency map.

The efficiency distributions of both maps are similar. Table VII shows the data selected for different operational points, comparing the values from the model and the experimental ones.
TABLE VII

PMSM FEA MODEL AND EXPERIMENTAL EFFICIENCY VALUES COMPARISON

\begin{tabular}{c|c|c|c}
\hline \hline $\begin{array}{c}\text { Angular } \\
\text { velocity } \\
(\mathbf{1} / \mathbf{m i n})\end{array}$ & Torque (Nm) & $\begin{array}{c}\text { PMSM Model } \\
\text { Efficiency } \\
\text { (p.u) }\end{array}$ & $\begin{array}{c}\text { PMSM } \\
\text { Experimental } \\
\text { Efficiency } \\
\text { (p.u) }\end{array}$ \\
\hline 750.3 & 1.2110 & 0.6240 & 0.5997 \\
\hline 1501 & 0.7998 & 0.7844 & 0.7316 \\
\hline 2001 & 0.5940 & 0.8082 & 0.7660 \\
\hline 2501 & 1.2010 & 0.8084 & 0.7928 \\
\hline 3001 & 0.7060 & 0.8236 & 0.8006 \\
\hline 3251 & 0.4012 & 0.7836 & 0.7413 \\
\hline 3501 & 0.2006 & 0.6724 & 0.6449 \\
\hline 4002 & 1.2010 & 0.8405 & 0.8477 \\
\hline 4200 & 0.7008 & 0.8234 & 0.7832 \\
\hline 4502 & 0.4012 & 0.7601 & 0.6754 \\
\hline \hline
\end{tabular}

The SSIM between the reference and the design optimization algorithm torque-speed-efficiency map is 0.983 . Thus the algorithm converges with relative error $1.7 \%$. The SSIM between FEA and experimental maps is 0.96 , i.e., the relative error between both maps is $4 \%$.

\section{System Torque-Speed-Efficiency Map}

Once compared both PMSM torque-speed-efficiency maps, the system efficiency map obtained with the FEA model can be compared with the experimental one. Fig. 14 (a) shows the PMSM-WP FEA model torque-speed-efficiency map, whereas Fig. 14 (b) shows the PMSM-WP experimental torque-speedefficiency map.

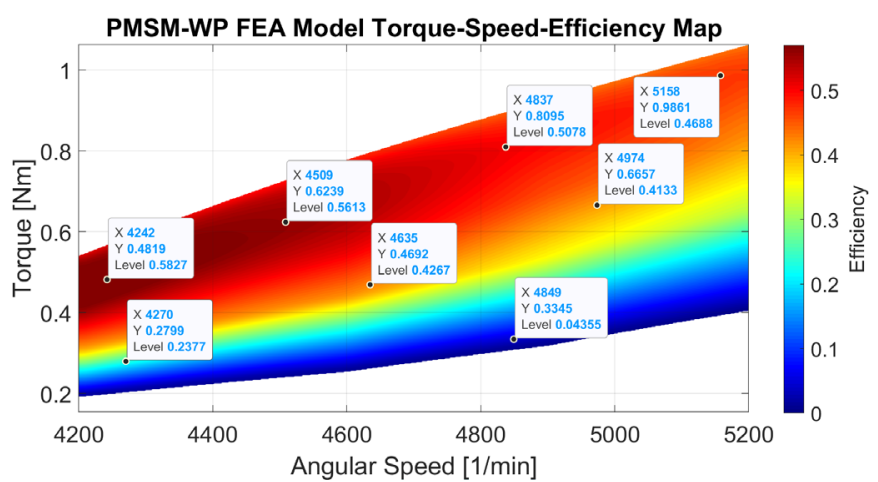

(a)

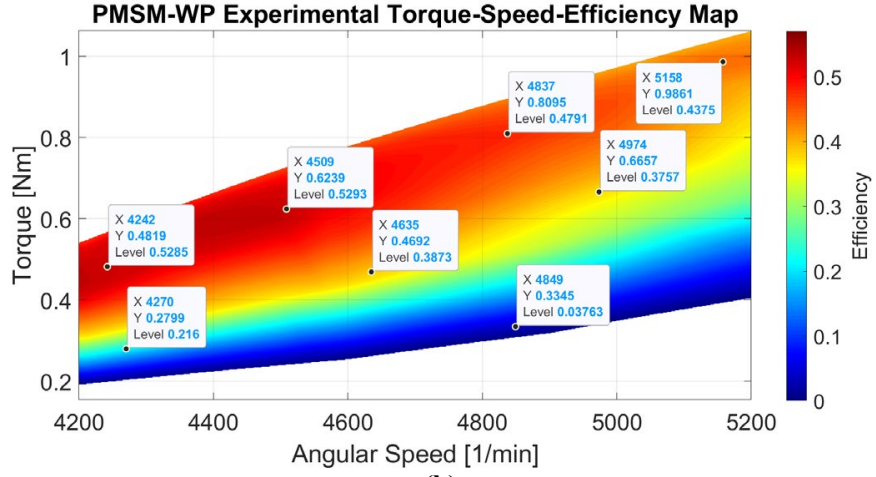

(b)

Fig. 14. (a) PMSM-WP FEA model torque-speed-efficiency map. (b) PMSMWP experimental torque-speed-efficiency map.

The relative SSIM between both maps is 0.99 , i.e., the relative error is $1 \%$.

Table VIII compares the operational points from the model and the experimental ones. 
TABLE VIII

PMSM-WP FEA MODEL AND EXPERIMENTAL EFFICIENCY VALUES COMPARISON

\begin{tabular}{c|c|c|c}
\hline \hline $\begin{array}{c}\text { Angular } \\
\text { velocity } \\
\text { (1/min) }\end{array}$ & $\begin{array}{c}\text { Torque } \\
\text { (Nm) }\end{array}$ & $\begin{array}{c}\text { Hydraulic-PMSM } \\
\text { Model Efficiency } \\
\text { (p.u) }\end{array}$ & $\begin{array}{c}\text { Hydraulic-PMSM } \\
\text { Experimental Efficiency } \\
\text { (p.u) }\end{array}$ \\
\hline 4242 & 0.4819 & 0.5827 & 0.5285 \\
\hline 4270 & 0.2799 & 0.2377 & 0.2160 \\
\hline 4509 & 0.6239 & 0.5613 & 0.5293 \\
\hline 4635 & 0.4692 & 0.4267 & 0.3873 \\
\hline 4849 & 0.3345 & 0.0436 & 0.0376 \\
\hline 4837 & 0.0895 & 0.5078 & 0.4791 \\
\hline 4974 & 0.6657 & 0.4133 & 0.3757 \\
\hline 5158 & 0.9861 & 0.4683 & 0.4375 \\
\hline \hline
\end{tabular}

Table IX shows the system efficiency values. As can be observed, the FEA model fits into the target efficiency levels. Nevertheless, it is observed an overall efficiency decrement for the experimental values. This shows the importance of taking into account some other variables when designing the PMSM using the proposed algorithm, such as the mechanical tolerances, the increment of iron losses due to the manufacturing process, or changes in the winding resistance, among others. However, the absolute errors remain low enough $(19.6 \mathrm{~W}, 14.6 \mathrm{~W}, 14.8 \mathrm{~W}, 12.4 \mathrm{~W}, 14 \mathrm{~W})$, thus allowing to validate the design-optimization process.

TABLE IX

PMSM-WP FEA MODEL AND EXPERIMENTAL EFFICIENCY LEVELS COMPARISON

\begin{tabular}{c|c|c|c|c}
\hline \hline $\begin{array}{c}\text { Angular } \\
\text { velocity } \\
(\mathbf{1} / \mathbf{m i n})\end{array}$ & $\begin{array}{c}\text { Torque } \\
\mathbf{( N m )}\end{array}$ & $\begin{array}{c}\text { Efficiency } \\
\mathbf{( p . u )}\end{array}$ & $\begin{array}{c}\text { Efficiency } \\
\text { Model } \\
(\mathbf{p . u})\end{array}$ & $\begin{array}{c}\text { Efficiency } \\
\text { Experimental } \\
(\mathbf{p . u})\end{array}$ \\
\hline 5200 & 1.06 & 0.43 & 0.4306 & 0.3967 \\
\hline 5100 & 1.00 & 0.45 & 0.4534 & 0.4261 \\
\hline 5000 & 0.9 & 0.48 & 0.4875 & 0.4561 \\
\hline 4900 & 0.8 & 0.49 & 0.4939 & 0.4638 \\
\hline 4700 & 0.7 & 0.50 & 0.5302 & 0.4893 \\
\hline \hline
\end{tabular}

\section{E. PMSM Characteristics}

This subsection presents the PMSM characteristics. Some geometric variables are discussed as well as the performance under rated conditions. Fig. 15 shows the PMSM prototype and the PMSM-WP assembly.

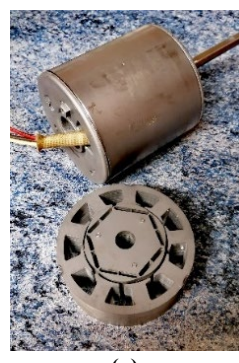

(a)

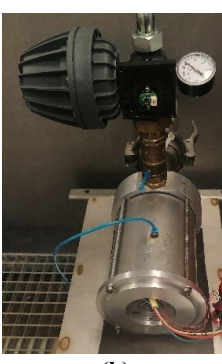

(b)

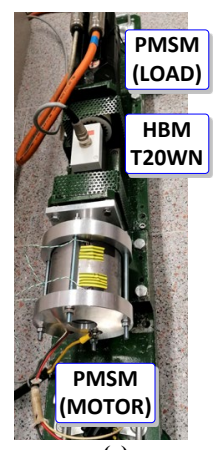

(c)
Fig. 15. (a) PMSM prototype assembly. (b) PMSM-WP system. (c) PMSM test bench.

As commented in this section, the outer stator diameter $D_{o s}$ was fixed due the size of the required application. Based on this parameter and the geometric rules defined in Section II, the design optimization algorithm finds the PMSM geometry for the desired performance. Table $\mathrm{X}$ summarizes the PMSM geometric variables.
TABLE X

PMSM GEOMETRY VALUES

\begin{tabular}{c|c}
\hline \hline Geometry Parameter & Values \\
\hline$g[\mathrm{~mm}]$ & 0.29 \\
\hline$D_{o r}[\mathrm{~mm}]$ & 54 \\
\hline$D_{o s}[\mathrm{~mm}]$ & 90 \\
\hline$L[\mathrm{~mm}]$ & 30 \\
\hline$h_{P M}[\mathrm{~mm}]$ & 2.7 \\
\hline$N_{p h}$ & 210 \\
\hline$d_{\text {wire }}[\mathrm{mm}]$ & 0.6 \\
\hline \hline
\end{tabular}

Table XI summarizes the general characteristics of the PMSM.

TABLE XI

PMSM CHARACTERISTICS

\begin{tabular}{c|c}
\hline \hline Characteristics & Value \\
\hline Number of phases & 3 \\
\hline Rated power [W] & 585 \\
\hline Rated Voltage $\left[\mathrm{V}_{\mathrm{RMS}}\right]$ & 200 \\
\hline Rated Current $\left[\mathrm{I}_{\mathrm{RMS}}\right]$ & 2 \\
\hline Rated Torque [N·m] & 1.24 \\
\hline Rated Speed [rpm] & 4501 \\
\hline Rated Efficiency [\%] & 84.2 \\
\hline Pole Pairs & 3 \\
\hline Number of Slots & 9 \\
\hline d-axis Inductance $\mathrm{L}_{\mathrm{d}}[\mathrm{mH}]$ & 4.2 \\
\hline q-axis Inductances $\mathrm{L}_{\mathrm{q}}[\mathrm{mH}]$ & 11.2 \\
\hline \hline
\end{tabular}

As shown in Table XI, the rated power of the motor is 585 $\mathrm{W}$. According to the IEC 60034-30-1 standard for electrical machines with premium efficiency class (IE4), machines with rated power of $600 \mathrm{~W}$ should have an efficiency of $84 \%$. Therefore, the designed machine matches with the premium efficiency standard.

\section{F. PMSM Time Dependent FEA Validation}

This subsection applies time-dependent FEA to validate the PMSM design under rated conditions. Time-dependent FEA results are compared against experimental acquisitions. Such simulation is performed using pure sinusoidal voltage sources with $200 \mathrm{~V}_{\text {RMS }}$. The same operational point is tested experimentally using the RENESAS YROTATE-IT-RX32T converter, which applies sinusoidal pulse width modulation (SPWM). Fig. 16 shows the time evolution of the phase current and mechanical torque.

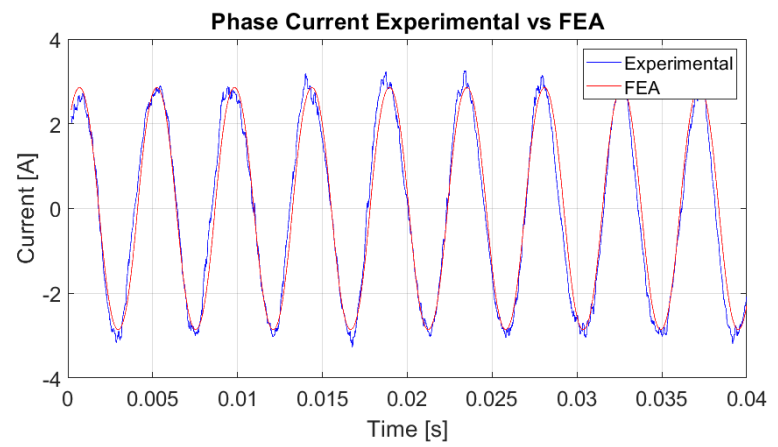

(a) 


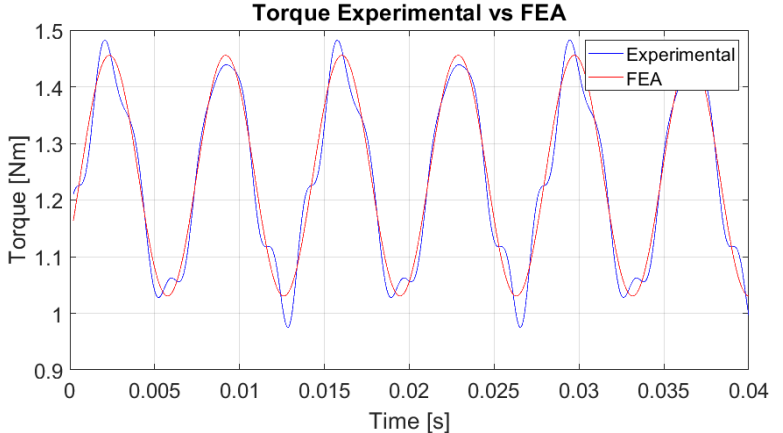

(b)

Fig. 16. (a) PMSM experimental vs FEA phase current at rated conditions. (b) PMSM experimental vs FEA torque at rated conditions

Fig. 16 (a) shows that the experimental and FEA time evolution current match in phase and magnitude. The experimental acquisition includes high frequency noise and a subharmonic component due to winding unbalance. The RMS values of the experimental and FEA currents are 2.09 and 2.02 A, respectively. Fig. 16 (b) shows the experimental and simulated torque waveform. The observed difference is mainly because the torque meter HBM T20WN/20NM (Torque: 0-10 $\mathrm{V}, \pm 0.2 \%$ ) is not only detecting the torque ripple of the PMSM acting as a motor but also the torque ripple of the load PMSM, which adds some distortion. The mean experimental and FEA torques are 1.237 and $1.240 \mathrm{Nm}$, respectively.

\section{G. Optimization Convergence and Computational Burden}

A target value for optimization convergence is $2 \%$ using the SSIM, i.e. $f_{o b j}=1-\mathrm{SSIM}=0.02$. Using the patternsearch optimization solver from MATLAB $\AA$, the design optimization algorithm converges with a relative difference of $1.7 \%$, thus accomplishing with the defined target value.

The design process of the PMSM prototype adapted to the

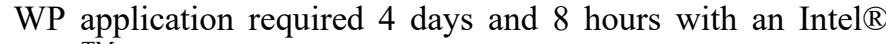
Core $^{\mathrm{TM}}$ i9-7940X $3.10 \mathrm{GHz}$ processor with $64 \mathrm{~GB}$ of RAM memory. Every optimization iteration requires between 24-40 seconds, being strictly dependent on the iron saturation. To limit the design-optimization time, the number of optimization iterations were limited to 10000 . The computational resources available are a processor. The time required to design the PMSM is affordable and avoids manufacturing costs, saving time and resources.

\section{CONCLUSIONS}

This study has proposed a methodology to design and optimize PMSMs by defining the desired torque-speedefficiency map by adapting its performance to the hydraulic characteristics of a specific WP application. It allows the designer to have full freedom to define the efficiency levels and distribution along the torque-speed map, including implicitly the distribution of power losses and power rating. The design optimization algorithm calculates the PMSM whose characteristics match the defined performance as closely as possible. The proposed methodology has been validated experimentally by designing and testing a PMSM adapted to a WP hydraulic application. In this application, the two operating points were selected according to initial specifications, which were defined by the torque, speed and system efficiency. Next, extra operating points were inferred by interpolating three points between the two initial ones in order to increase the resolution of the objective torque-speed-efficiency map. With this reference map, the design-optimization process starts. From the resulting optimized motor, the FEA torque-speed-efficiency map was obtained, attaining the efficiency levels defined as a target. The SSIM between the reference and the design optimization algorithm torque-speed-efficiency map is 0.983 , thus the algorithm converges with $1.7 \%$ relative error. Next, the prototype was manufactured and tested and the experimental efficiency map was obtained. The results obtained show high fidelity between the FEA and experimental torque-speedefficiency maps. The relative error between both maps was only $4 \%$. After validating the PMSM performance, the efficiency of the FEA PMSM-WP system was compared against the experimental one, obtaining a relative error of $1 \%$.

\section{REFERENCES}

[1] G. H. Jang, J. H. Ahn, B. O. Kim, D. H. Lee, J. S. Bang, and J. Y. Choi, "Design and Characteristic Analysis of a High-Speed Permanent Magnet Synchronous Motor Considering the Mechanical Structure for HighSpeed and High-Head Centrifugal Pumps," IEEE Trans. Magn., vol. 54, no. 11, Nov. 2018, doi: 10.1109/TMAG.2018.2845874.

[2] J. Pyrhonen, T. Jokinen, and V. Hrabovcová, Design of rotating electrical machines, 2nd edn. Hoboken: Wiley, 2013.

[3] N. Bianchi, T. M. Jahns, and W. . (2004. 10. 05. (Seattle, Design, analysis, and control of interior PM synchronous machines: tutorial course notes ; Seattle, Oct. 5, 2004. CLEUP, 2004.

[4] T. R. Brinner, R. H. McCoy, and T. Kopecky, "Induction versus permanent-magnet motors for electric submersible pump field and laboratory comparisons," IEEE Trans. Ind. Appl., vol. 50, no. 1, pp. 174 181, 2014, doi: 10.1109/TIA.2013.2288203.

[5] R. Antonello, M. Carraro, A. Costabeber, F. Tinazzi, and M. Zigliotto, "Energy-Efficient Autonomous Solar Water-Pumping System for Permanent-Magnet Synchronous Motors," IEEE Trans. Ind. Electron., vol. 64, no. 1, pp. 43-51, Jan. 2017, doi: 10.1109/TIE.2016.2595480.

[6] B. Singh and S. Murshid, "A grid-interactive permanent-magnet synchronous motor-driven solar water-pumping system," IEEE Trans. Ind. Appl., vol. 54, no. 5, pp. 5549-5561, Sep. 2018, doi: 10.1109/TIA.2018.2860564.

[7] S. Murshid and B. Singh, "Energy-efficient single-stage solar PV powered sensorless PMSM drive for water pumping," IET Renew. Power Gener., vol. 13, no. 13, pp. 2267-2277, Oct. 2019, doi: 10.1049/ietrpg.2018.6205.

[8] S. Murshid and B. Singh, "Implementation of PMSM Drive for a Solar Water Pumping System," in IEEE Transactions on Industry Applications, Sep. 2019, vol. 55, no. 5, pp. 4956-4964, doi: 10.1109/TIA.2019.2924401.

[9] H. Jung, D. Kim, C. B. Lee, J. Ahn, and S. Y. Jung, "Numerical and experimental design validation for adaptive efficiency distribution compatible to frequent operating range of IPMSM," IEEE Trans. Magn., vol. 50, no. 2, Feb. 2014, doi: 10.1109/TMAG.2013.2285409.

[10] L. Xu, W. Zhao, G. Liu, and C. Song, "Design Optimization of a SpokeType Permanent-Magnet Vernier Machine for Torque Density and Power Factor Improvement," IEEE Trans. Veh. Technol., vol. 68, no. 4, pp. 3446-3456, Apr. 2019, doi: 10.1109/TVT.2019.2902729.

[11] H. Fang and D. Wang, "A Novel Design Method of Permanent Magnet Synchronous Generator from Perspective of Permanent Magnet Material Saving," IEEE Trans. Energy Convers., vol. 32, no. 1, pp. 48-54, Mar. 2017, doi: 10.1109/TEC.2016.2621133.

[12] X. Sun, Z. Shi, G. Lei, Y. Guo, and J. Zhu, "Analysis and Design Optimization of a Permanent Magnet Synchronous Motor for a Campus Patrol Electric Vehicle," IEEE Trans. Veh. Technol., vol. 68, no. 11, pp. 10535-10544, Nov. 2019, doi: 10.1109/TVT.2019.2939794.

[13] J. Du, X. Wang, and H. Lv, "Optimization of Magnet Shape Based on Efficiency Map of IPMSM for EVs," IEEE Trans. Appl. Supercond., vol. 26, no. 7, Oct. 2016, doi: 10.1109/TASC.2016.2594834.

[14] M. Fasil, N. Mijatovic, B. B. Jensen, and J. Holboll, "Finite-Element Model-Based Design Synthesis of Axial Flux PMBLDC Motors," IEEE Trans. Appl. Supercond., vol. 26, no. 4, Jun. 2016, doi: 10.1109/TASC.2016.2537743. 
[15] D. M. Ionel and M. Popescu, "Ultrafast finite-element analysis of brushless PM machines based on space-time transformations," IEEE Trans. Ind. Appl., vol. 47, no. 2, pp. 744-753, Mar. 2011, doi: 10.1109/TIA.2010.2102733.

[16] H. Chen, X. Liu, N. A. O. Demerdash, A. M. El-Refaie, Z. Chen, and J. $\mathrm{He}$, "Computationally efficient optimization of a five-phase fluxswitching PM machine under different operating conditions," IEEE Trans. Veh. Technol., vol. 68, no. 7, pp. 6495-6508, Jul. 2019, doi: 10.1109/TVT.2019.2915239.

[17] H. Dhulipati, E. Ghosh, S. Mukundan, P. Korta, J. Tjong, and N. C. Kar, "Advanced design optimization technique for torque profile improvement in six-phase pmsm using supervised machine learning for direct-drive ev," IEEE Trans. Energy Convers., vol. 34, no. 4, pp. 20412051, Dec. 2019, doi: 10.1109/TEC.2019.2933619.

[18] J. Y. Alsawalhi and S. D. Sudhoff, "Design optimization of asymmetric salient permanent magnet synchronous machines," IEEE Trans. Energy Convers., vol. 31, no. 4, pp. 1315-1324, Dec. 2016, doi: 10.1109/TEC.2016.2575138

[19] O. Wallscheid and J. Böcker, "Global identification of a low-order lumped-parameter thermal network for permanent magnet synchronous motors," IEEE Trans. Energy Convers., vol. 31, no. 1, pp. 354-365, Mar. 2016, doi: 10.1109/TEC.2015.2473673.

[20] O. Beik, "Design Optimization of a PM Motor: A Practical Approach for Mass Production," IEEE Trans. Energy Convers., vol. 35, no. 4, pp. 1849-1858, Dec. 2020, doi: 10.1109/TEC.2020.2991531.

[21] A. Al-Timimy et al., "Design and Losses Analysis of a High Power Density Machine for Flooded Pump Applications," IEEE Trans. Ind. Appl., vol. 54, no. 4, pp. 3260-3270, Jul. 2018, doi: 10.1109/TIA.2018.2821623.

[22] "ISO 5199:2002(en), Technical specifications for centrifugal pumps Class II."

[23] C. Candelo-Zuluaga, A. Garcia Espinosa, J. R. Riba, and P. Tubert, "PMSM Design For Achieving a Target Torque-Speed-Efficiency Map," IEEE Trans. Veh. Technol., vol. 69, no. 12, pp. 14448-14457, 2020, doi: 10.1109/TVT.2020.3040313

[24] Z. Wang, A. C. Bovik, H. R. Sheikh, and E. P. Simoncelli, "Image Quality Assessment: From Error Visibility to Structural Similarity," IEEE Trans. Image Process., vol. 13, no. 4, pp. 600-612, Apr. 2004, doi: 10.1109/TIP.2003.819861.

[25] F. Verbelen, A. Abdallh, H. Vansompel, K. Stockman, and P. Sergeant, "Sizing Methodology Based on Scaling Laws for a Permanent Magnet Electrical Variable Transmission," IEEE Trans. Ind. Electron., vol. 67, no. 3, pp. 1739-1749, Mar. 2020, doi: 10.1109/TIE.2019.2903763.

[26] N. Bernard, R. Missoum, L. Dang, N. Bekka, H. Ben Ahmed, and M. E. H. Zaim, "Design Methodology for High-Speed Permanent Magnet Synchronous Machines," IEEE Trans. Energy Convers., vol. 31, no. 2, pp. 477-485, Jun. 2016, doi: 10.1109/TEC.2015.2513669.

[27] C. Candelo-Zuluaga, A. G. Espinosa, J.-R. Riba, P. T. Blanch, and F. J. Descalzo, "Water-Pumping Permanent Magnet Synchronous Motor Optimization Based on Customized Torque-Speed Operating Area and Performance Characteristics," Dec. 2019, pp. 1471-1476, doi: 10.1109/iecon.2019.8927579.

[28] C. Lopez-Torres, C. Colls, A. Garcia, J.-R. Riba, and L. Romeral, "Development of a Behavior Maps Tool to Evaluate Drive Operational Boundaries and Optimization Assessment of PMa-SynRMs," IEEE Trans. Veh. Technol., vol. 67, no. 8, pp. 6861-6871, Aug. 2018, doi: 10.1109/TVT.2018.2823339.

[29] J. H. Lee, J. W. Kim, J. Y. Song, Y. J. Kim, and S. Y. Jung, “A Novel Memetic Algorithm Using Modified Particle Swarm Optimization and Mesh Adaptive Direct Search for PMSM Design," in IEEE Transactions on Magnetics, Mar. 2016, vol. 52, no. 3, doi: 10.1109/TMAG.2015.2482975.

[30] T. G. Kolda, R. M. Lewis, and V. Torczon, "Optimization by direct search: New perspectives on some classical and modern methods," SIAM Rev., vol. 45, no. 3, pp. 385-482, 2003, doi: $10.1137 / \mathrm{S} 003614450242889$.

[31] "IEC 60034-30-1:2014 Rotating Electrical Machines-Part 30-1: Efficiency classes of line operated AC motors (IE code)."

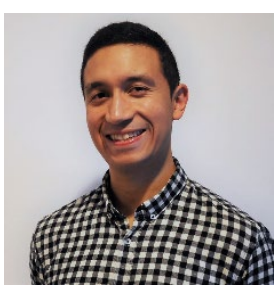

\section{BIOGRAPHIES}

Carlos Candelo-Zuluaga received the M.S. in industrial engineering from the Universitat Politècnica de Catalunya, Barcelona, Spain. Where he is currently working toward the Ph.D. degree in electrical engineering. His research interest includes the design and optimization of permanent magnet synchronous motors.

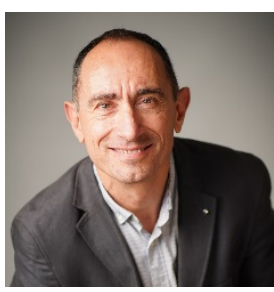

Jordi-Roger Riba (M'09) was born in Igualada, Spain, in 1966. He received the M.S. and Ph.D. degrees in physics from the Universitat de Barcelona, Barcelona, Spain, in 1990 and 2000, respectively. In 1992, he joined the Universitat Politècnica de Catalunya, where he is currently a Full professor. He is currently with the Motion Control and Industrial Applications Research Group (MCIA). His current research interests include modeling and simulation of electromagnetic devices, electrical machines and high-voltage engineering.

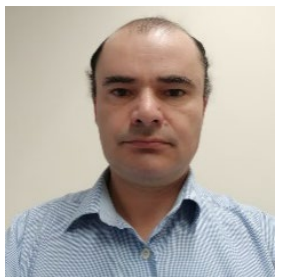

Antonio Garcia received the M.S. degree in electrical engineering and the Ph.D. degree from the Universitat Politècnica de Catalunya, in 2000 and 2005, respectively. He is with the Motion and Industrial Control Research Group (MCIA). His research interests include electromagnetic devices, electric machines, variable-speed drive systems, and fault-detection algorithms.

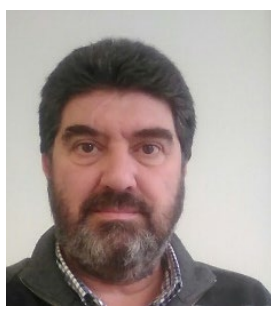

Pere Tubert Blanch was born in Crespià, Spain, in 1966. He received the mechanical engineering degree from the Universitat Politècnica de Catalunya in 1988. He joined to ESPA corporation at 1989 being the technical and quality director while implementing ISO 9001. He is currently working as a mechanical designer in Midtal Talentos S.L company. 